\title{
Symptoms-based Fuzzy-Logic Approach for COVID-19 Diagnosis
}

\author{
Maad Shatnawi ${ }^{1}$ \\ Department of Electrical Engineering Technology \\ Higher Colleges of Technology \\ Abu Dhabi, UAE
}

Anas Shatnawi ${ }^{2}$

Berger-Levrault

Montpellier, France

\author{
Zakarea AlShara ${ }^{3}$ \\ Department of Software Engineering \\ Jordan University of Science and Technology \\ Irbid, Jordan
}

\author{
Ghaith Husari ${ }^{4}$ \\ Department of Computer Science \\ East Tennessee State University \\ Johnson City, Tennessee
}

\begin{abstract}
The coronavirus (COVID-19) pandemic has caused severe adverse effects on the human life and the global economy affecting all communities and individuals due to its rapid spreading, increase in the number of affected cases and creating severe health issues and death cases worldwide. Since no particular treatment has been acknowledged so far for this disease, prompt detection of COVID-19 is essential to control and halt its chain. In this paper, we introduce an intelligent fuzzy inference system for the primary diagnosis of COVID-19. The system infers the likelihood level of COVID-19 infection based on the symptoms that appear on the patient. This proposed inference system can assist physicians in identifying the disease and help individuals to perform self-diagnosis on their own cases.
\end{abstract}

Keywords-COVID-19; coronavirus diagnosis; fuzzy inference system; fuzzy logic; fuzzy rules; expert systems

\section{INTRODUCTION}

The Coronavirus disease 2019 (COVID-19) pandemic has seriously affected all aspects of our life including health, education, economy, travel, and entertainment. Spreading rapidly across borders, the coronavirus disease has created a global health crisis and caused numerous death cases all over the world. Coronaviruses are a wide group of viruses that cause sickness starting from the common cold and up to very severe infections leading to death in several situations [1-3]. The common COVID-19 symptoms that are normally seen within 2 to 14 days are cold, dry cough, fever, flu, breathing difficulties, throat sore, and headache [4-8].

Since no therapeutic drug has been confirmed for COVID19 till this date, the early diagnosis and preventions are essential to control and break down the chain of COVID-19 by immediate isolation of the infected person from the healthy population [9] [10]. The most common methods that global healthcare systems are currently using for Covid-19 identification are Real-Time Polymerize Chain Reaction (RTPCR) tests in addition to chest Computerized Tomography (CT) scan and X-ray imaging. However, PCR testing requires several hours to get the results and suffers from high false positive rates and false negative rates which means it does not identify all infections, and therefore, PCR should not be used as the only criterion for detecting COVID-19 patients [11-13].

A number of studies reported that chest CT scan has considerably higher COVID-19 diagnosis sensitivity than RTPCR. On the other hand, CT scans and X-rays have the following limitations. First, CT scans have high false negative rates, as they are unable to distinguish coronary tissue from non-coronary tissue. A large number of COVID-19 patients have normal chest CTs or X-rays. Second, CT scans are unable to discriminate between cancerous tissue, cysts, and coronary tissue. Third, the nonappearance of an anomaly on either a chest X-ray or CT scan does not necessarily eliminate being COVID-19 infected. Fourth, chest CT scans and X-ray cannot precisely differentiate between COVID-19 and other respiratory infections such as seasonal flu. Fifth, CT scanning machines are complex equipment that should be carefully sanitized between potential COVID-19 patients, and there is a risk that the virus remains on the surfaces of CT scanning rooms. Finally, moving potential COVID-19 patients to and from a CT scanning room increases the hazard of spreading the virus within healthcare centers [13-18].

As a result, integrating these methods with a symptombased diagnosis method will lead to more accurate identification results. In this work, we propose a smart fuzzy inference system to diagnose the COVID-19 based on the symptoms that appear on the patient.

The rest of the paper is organized as follows. Section II presents a background of the fuzzy inference systems and its applications in medical diagnosis. In Section III, we describe the design of our COVID-19 inference system. We evaluate the effectiveness of our approach in Section IV. Section V presents concluding remarks and highlights future directions.

\section{FUZZY INFERENCE SYSTEMS: BACKGROUND AND RELATED WORK}

Fuzzy Inference Systems (FIS) use fuzzy reasoning in order to represent the knowledge of experts about certain problems in human-like decision-making. These systems are based on fuzzy logic modeling and allow attaining solutions based on 
linguistic terms. They are principally useful in cases where human knowledge is available but there is no sufficient information to feed traditional mathematical model variables [19-25]. The fuzzy inference system is made up of four main modules; fuzzification module, knowledge base, inference engine, and defuzzification module as shown in Fig. 1.

The most commonly used fuzzy inference technique is the Mamdani model [26, 27]. The Mamdani fuzzy inference process is performed in four consequent stages; fuzzification, rule evaluation, rule output aggregation, and defuzzification. The fuzzification module maps the crisp input value into a degree of membership of fuzzy sets by applying fuzzification membership functions. A membership function returns a value between zero (for non-membership) and one (for fullmembership). The Knowledge base includes the IF-THEN rules that are provided by field experts. The rules are in the form [28]:

IF (A is $\mathrm{x}$ ) AND ( $\mathrm{B}$ is $\mathrm{y})$ AND ( $\mathrm{C}$ is $\mathrm{z})$... THEN ( $\mathrm{R}$ is $\mathrm{m}$ )

where $\mathrm{A}, \mathrm{B}$, and $\mathrm{C}$ represent the input variables while $\mathrm{x}, \mathrm{y}$, and $\mathrm{z}$ represent the corresponding linguistic terms (e.g., yes, no), $\mathrm{R}$ represents the rule output variable and $\mathrm{m}$ represent the corresponding linguistic term (e.g., high risk, medium risk, low risk). The defuzzification module converts the output of the inference engine into a crisp output value. The Centroid or the Center of Gravity (COG) method is the most popular defuzzification technique where the weighted average of the area bounded by the aggregated membership function curve of the output variable is considered the crisp output value $[13,29$, 30].

The final defuzzified output value using the centroid method is calculated by the following equation:

$d_{C O G}(M)=\frac{\int_{-M}^{M} M(z) z d z}{\int_{-M}^{M} M(z) d z}$

where $M$ represents the membership function of the output variable.

Fuzzy inference systems have been widely used in the medical diagnosis of different diseases. Lee and Wang [31] presented a fuzzy expert system based on fuzzy ontology as a decision support model for diabetes. Mayilvaganan and Rajeswari [32] proposed high blood pressure fuzzy logic classifier. Ekong et al. [33], Djam et al. [34] and Sharma et al. [35] proposed fuzzy expert systems for malaria diagnosis. Chandra [36] suggested a fuzzy expert system for migraine analysis and diagnosis.

Several fuzzy inference models have been proposed for heart disease diagnosis such as Kumar [37], Adeli and Neshat [38], Kumar and Kaur [39], Kasbe and Pippal [40], Allahverdi et al. [41], Oad et al. [42] and Subbulakshmi et al. [43]. A number of fuzzy inference models were proposed for cancer detection [44] such as Keleş et al. [45], Balanica et al. [46] and Latha et al. [47] for breast cancer diagnosis, Lavanya et al. [48] for lung cancer diagnosis, and Saritas et al. [49] for prostate cancer diagnosis. Kolhe et al. [50] presented a fuzzy-logic based approach for disease-diagnosis in crops.

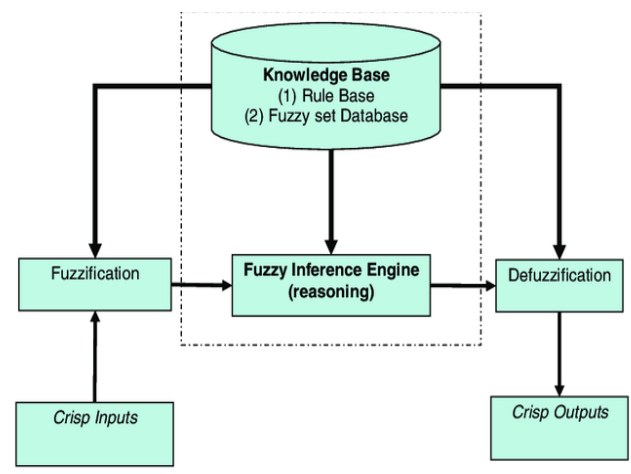

Fig. 1. The Fuzzy Inference System Block Diagram.

Patel et al. [51], Anand et al. [52], Mishra et al. [53] and Sundararaman et al. [54] proposed Asthma fuzzy diagnosis systems. Damirchi-Darasi et al. [55] proposed fuzzy rule-based expert system for the diagnosis of spinal cord disorders. Kadhim et al. [56] suggested a fuzzy expert system for back pain diagnosis. Zarei et al. [57] suggested a fuzzy modeling and control of HIV infection and [58] proposed diagnosis of HIV/AIDs using Fuzzy Cluster Means Algorithm.

Faisal et al. [59] employed an Adaptive Neuro-Fuzzy Inference System to predict the degree of risk of dengue patients. Saikia and Dutta [60] applied FIS to diagnosis the Dengue disease. Alrashoud [61] proposed a Hierarchical Fuzzy Inference system for dengue fever diagnosis. Shaaban et al. [13] introduced a hybrid COVID-19 diagnosis system through fuzzy inference and deep neural networks based on four laboratory data which are White Blood Cell (WBC), Lymphocyte (LYM), Monocytes (MON), and Locate Dehydrogenase (LDH).

\section{COVID-19 INFERENCE SYSTEM}

In this work, a smart fuzzy inference system is proposed for the early detection of COVID-19 based on the patient symptoms including cold, cough, fever, flu, breathing difficulties, throat infection and headache [8]. The proposed system infers the likelihood level of COVID-19 infection based on the symptoms that appear on the patient. The COVID-19 fuzzy inference system is designed by identifying the input and output variables in addition to the fuzzy sets and membership functions of each variable. Afterward, a set of fuzzy rules that are connecting input variables with output variables are set. The proposed inference system is aims at diagnosing the COVID-19 based on the patient data.

We applied the Mamdani Fuzzy model to build the COVID-19 inference system. We define 9 symptoms as the input variables to the inference system. We group these variables into two categories; most common symptoms and less common symptoms. The most common symptoms category includes fever, tiredness, and dry cough while the less common symptoms category includes diarrhea, sore throat, headache, conjunctivitis, loss of taste or smell, and breathing difficulties. The output variable is risk of being COVID-19 infected. The COVID-19 inference system is illustrated in Fig. 2. 


\section{A. Membership Functions}

Each input variable has two Gaussian membership functions as shown in Table I. The Gaussian membership function gaussmf $[\sigma \mu]$ is defined by its mean $\mu$ and standard deviation $\sigma$. The fever variable is represented by the body temperature which ranges between 36.5 and $42^{\circ} \mathrm{C}$ as presented in Fig. 3 while each of the remaining input variables has a level in the range from 0 to 5 as indicated in Fig. 4 [62, 63]. The output variable ranges from 0 to 100 and it has four Gaussian membership functions; low risk, medium risk, high risk and very high risk as presented in Fig. 5.

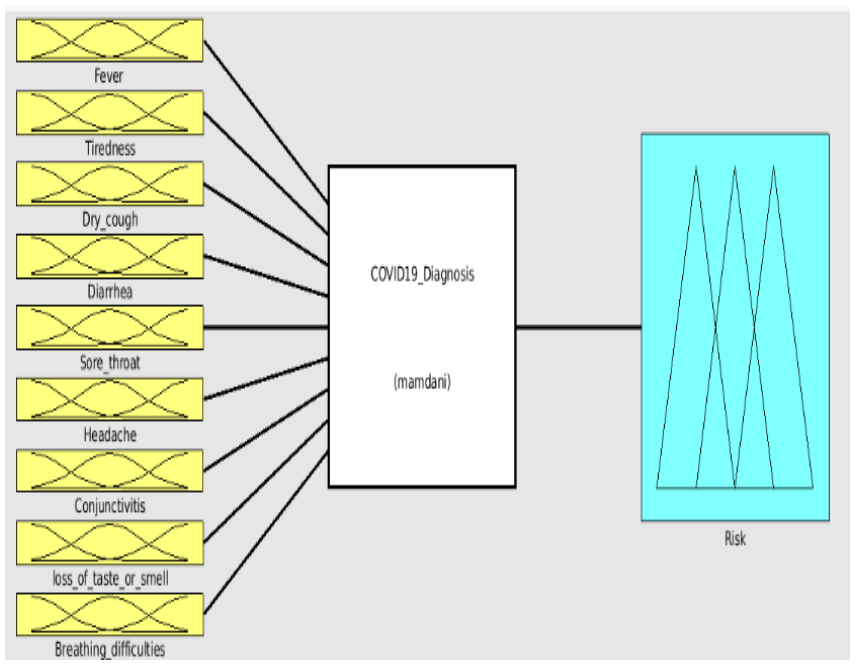

Fig. 2. COVID-19 Fuzzy Inference System.

TABLE I. MEMBERSHIP FUNCTIONS OF THE INPUT VARIABLES

\begin{tabular}{|l|l|l|l|l|}
\hline $\begin{array}{l}\text { Num } \\
\text { ber }\end{array}$ & $\begin{array}{l}\text { Variable } \\
\text { name }\end{array}$ & $\begin{array}{l}\text { Rang } \\
\text { e }\end{array}$ & $\begin{array}{l}\text { Membership } \\
\text { Function 1 (No) }\end{array}$ & $\begin{array}{l}\text { Membership } \\
\text { Function 2 (Yes) }\end{array}$ \\
\hline 1 & Fever & $\begin{array}{l}36.5- \\
42^{\circ} \mathrm{C}\end{array}$ & $\begin{array}{l}\text { 'gaussmf',[0.5 } \\
36.5\end{array}$ & 'gaussmf',[2 42] \\
\hline 2 & Tiredness & $0-5$ & 'gaussmf',[0.7 0] & 'gaussmf',[1.85 5] \\
\hline 3 & Dry cough & $0-5$ & 'gaussmf',[0.7 0] & 'gaussmf',[1.85 5] \\
\hline 4 & Diarrhea & $0-5$ & 'gaussmf',[0.7 0] & 'gaussmf',[1.85 5] \\
\hline 5 & Sore throat & $0-5$ & 'gaussmf',[0.7 0] & 'gaussmf',[1.85 5] \\
\hline 6 & Headache & $0-5$ & 'gaussmf',[0.7 0] & 'gaussmf',[1.85 5] \\
\hline 7 & $\begin{array}{l}\text { Conjunctiviti } \\
\text { s }\end{array}$ & $0-5$ & 'gaussmf',[0.7 0] & 'gaussmf',[1.85 5] \\
\hline 8 & $\begin{array}{l}\text { Loss of taste } \\
\text { or smell }\end{array}$ & $0-5$ & 'gaussmf',[0.7 0] & 'gaussmf',[1.85 5] \\
\hline 9 & $\begin{array}{l}\text { Breathing } \\
\text { difficulties }\end{array}$ & $0-5$ & 'gaussmf',[0.7 0] & 'gaussmf',[1.85 5] \\
\hline
\end{tabular}

(1)

Fig. 3. The Fever Membership Functions.

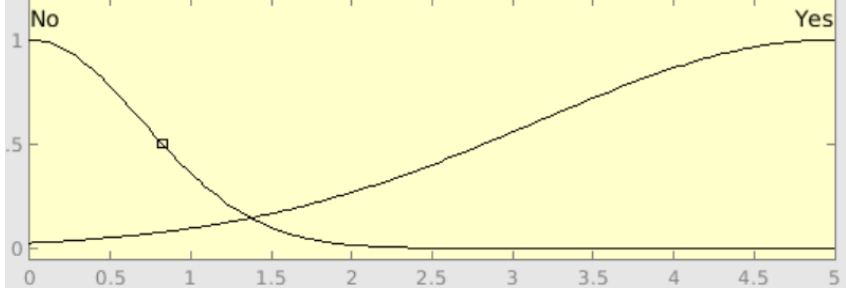

Fig. 4. The Tiredness Membership Functions.

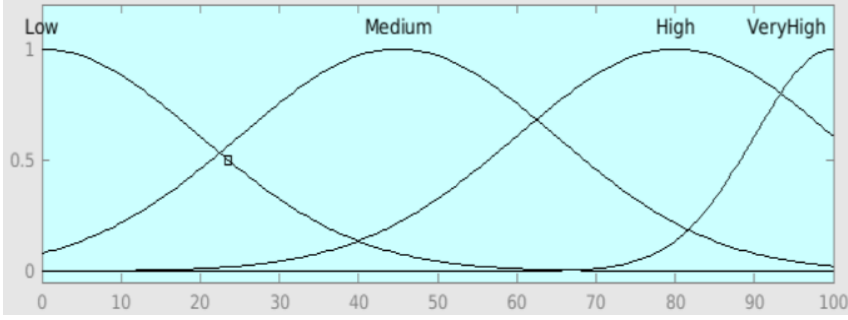

Fig. 5. The Risk of being COVID-19 Infected Membership Functions.

\section{B. Fuzzy Rules}

We define the following linguistic fuzzy rules:

- Rule 1: If 3 symptoms of Category-1 AND at least 4 symptoms of Category-2 are present $\rightarrow$ Very high risk of COVID-19 infection.

- Rule 2: If 3 symptoms of Category-1 AND less than 4 symptoms of Category-2 are present $\rightarrow$ High risk of COVID-19 infection.

- Rule 3: If the 3 symptoms of Category-1 are present $\rightarrow$ High risk of COVID-19 infection.

- Rule 4: If 2 symptoms of Category-1 AND at least 2 symptoms of Category-2 are present $\rightarrow$ High risk of COVID-19 infection.

- Rule 5: If 1 symptom of Category-1 AND at least 4 symptoms of Category-2 are present $\rightarrow$ High risk of COVID-19 infection.

- Rule 6: If 2 symptoms of Category-1 AND 1 symptom of Category- 2 are present $\rightarrow$ Medium risk of COVID19 infection.

- Rule 7: If 1 symptom of Category-1 AND 3 symptoms of Category-2 are present $\rightarrow$ Medium risk of COVID19 infection.

- Rule 8: If 1 symptom of Category-1 AND 2 symptoms of Category- 2 are present $\rightarrow$ Medium risk of COVID19 infection.

- Rule 9: If no symptoms of Category-1 AND 6 symptoms of Category- 2 are present $\rightarrow$ Medium risk of COVID-19 infection.

- Rule 10: If 2 symptoms of Category-1 AND no symptoms of Category-2 are present $\rightarrow$ Low risk of COVID-19 infection. 
- Rule 11: If only 1 symptom of Category-1 AND 1 symptom of Category-2 are present $\rightarrow$ Low risk of COVID-19 infection.

- Rule 12: If only 1 symptom of Category-1 is present AND no symptoms of Category- $\rightarrow$ Low risk of COVID-19 infection.

- Rule 13: If no symptoms of Category-1 AND less than 6 symptoms of Category-2 are present $\rightarrow$ Low risk of COVID-19 infection.

\section{Defuzzification of the Output}

Based on the input patient symptoms, the inference system initiates a set of fuzzy rules where each rule produces an output. Fuzzy operator "min" was used for generating the output fuzzy set by taking every rule that satisfied the AND operational logic for a given set of input values. Then the output fuzzy set of each rule was combined into a single fuzzy set by the aggregation process. The single fuzzy set was defuzzified into a single numeric output value using the Centroid method to determine the percentage risk level of being COVID-19 infected.

\section{System TESTING AND EVALUATION}

This section presents the evaluation of our approach in the following terms: (a) system validation based on the feedback of field experts and (b) system testing using generated mock patient data.

\section{A. System Validation}

For the evaluation of the proposed system, we define two main research questions (RQs) and received feedback from the field experts in the healthcare domain using a survey. The RQs are:

- RQ1: Are the COVID-19 Symptoms considered by our approach correct? The goal of this research question is to evaluate the list of COVID-19 symptoms that are used to build our approach.

- RQ2: Are the fuzzy rules correct? The goal of this research question is to evaluate the correctness of the set of fuzzy rules that are used by our approach to decide whether a person is infected by COVID-19 or not.

1) Study design: To ease the accessibility to the survey, we created a web-based survey using Google forms ${ }^{l}$. To test the relevance of the survey's questions before publishing, we conducted a pilot with five candidate participants from the healthcare domain. Each tester practitioner evaluated all questions and their related answers. As a result, they propose minor revisions of the survey. The survey was prepared based on three main sections as follows:

- The first section aims to allow us to describe the participants of this survey by collecting general information about them such as their ages, levels of experience in healthcare and medicine, professions, organizations and countries.

- The second section aims to evaluate the correctness of the set of symptoms related to COVID-19. To this end, each practitioner is asked to select a set (subset) of COVID-19 symptoms among the ones used in our approach. In order to identify COVID-19 symptoms that are not used by our approach, we make it also possible for a practitioner to add new COVID-19 symptoms.

- The last section includes questions related to the evaluation of the fuzzy rules defined in our approach. We asked the participants to evaluate each rule based on three options: Totally Agreed, Partially Agreed and Not Agreed. Totally agreed means that participants confirm our rule are correct following their experiences. Partially agreed refers to the case where participants agreed with this rule, but they do not consider it as correct in all cases. Meaning, the rules are correct for most cases, but not all compared to the COVID-19 patients based on their experiences. Not agreed means that participants do not agree with this rule. That means the rule should be modified.

To avoid prejudice, the survey was distributed to diverse participants from different health professions, levels of experience, organizations and countries. This distribution is based on social media and direct contact of health organizations such as hospitals and medical centers. One hundred participants have been invited to participate in the survey. They also have been requested to forward the survey to their networks.

\section{2) Results}

a) Participants: We have received 90 responses in total from participants from 11 different countries on four continents. The participants are also from different professions as presented in Fig. 6 where they cover almost all health domains that are related to COVID-19. Following their experience in the health domain, $58.9 \%, 28.8 \%$ and $12.2 \%$ of the participants have respectively more than 10 years, between 5 and 10 years and less than 4 years. The results show that $56.2 \%, 30 \%, 4.5 \%$ and $3.4 \%$ of the participants work respectively in Hospitals, Medical Centers, Universities and Pharmacies. As a result, the participants are diverse in their professions, type of health organizations, levels of experiences and geographical areas which means that they represent a good-enough sample that does not include prejudice in the answers to the survey questions.

b) $R Q 1$ : Are the COVID-19 Symptoms considered by our approach correct?

The results of the survey show that $90 \%$ of the participants agreed with us that these symptoms can be strongly used in COVID-19 diagnoses.

${ }^{1}$ This survey is accessible through:

https://docs.google.com/forms/d/e/1FAIpQLScDpa2uBCJg6366I7vOtFjVd91CEt_nh8k4QXc5k0vZ2xv6Q/viewform 


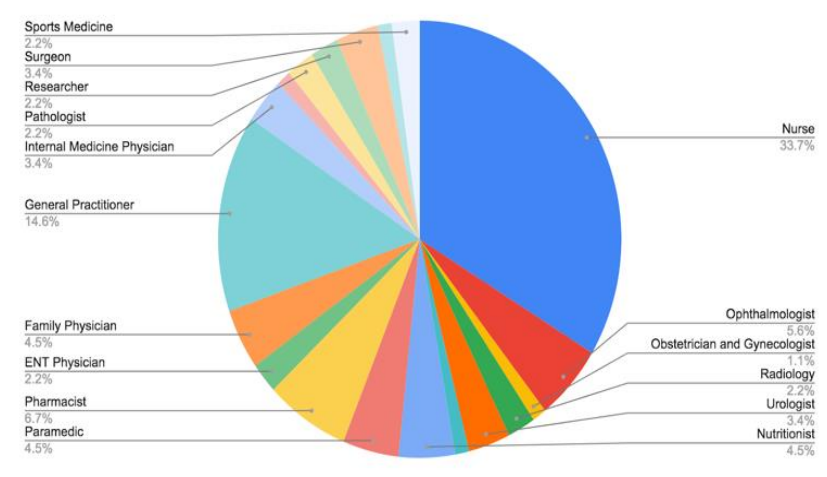

Fig. 6. Professions of the Survey Participants.

Fig. 7 shows the results of the evaluation of COVID-19 symptoms we used in our approach. The results show that the participants agreed with us for most of these symptoms. 6 of these symptoms (i.e., fever, breathing difficulties, loss of taste or smell, headache, dry cough, and tiredness) have been selected by more than $82 \%$ of the participants where fever is ranked as number one by $92.2 \%$ of the participants. The sore throat and diarrhea symptoms have been also selected by a quite number of participants. This means that the symptoms considered in our approach are representative compared to real COVID-19 cases based on the experience of the participants.

As it is allowed for the participants to add extra COVID-19 symptoms, we received only two extra symptoms: the stress and the body pain where each has been selected by one practitioner. These are rare symptoms. Thus, their absence will not negatively impact our approach.

Further, the results show that $85.5 \%$ of the participants agreed with us that Fever, Tiredness and Dry cough have more correlation with COVID-19 than the other Symptoms (from Question 8 in the survey). This confirms our decision to include these three symptoms in Category-1 that have higher weights in the fuzzy rules.

\section{c) $R Q 2:$ Are the fuzzy rules correct?}

Fig. 8 shows the results of evaluating the fuzzy rules. These results show that all of the rules are either partially or totally accepted by more than $80 \%$ of the participants. For example, Rule 1 has been accepted by $97.88 \%(77.88 \%+20 \%)$ of the participants. This means that the fuzzy rules can be used to build the COVID-19 inference system.

\section{B. System Testing}

Based on a certain input of patient symptoms, the inference system initiates a set of fuzzy rules where each rule produces an output. Then, aggregation and defuzzification is performed to generate a single overall output through the process of
Centroid calculation. This final output represents the percentage risk of being COVID-19 infected. The proposed system is tested on some mock patient cases and the results are presented in Table II. Fig. 9 illustrates the rule evaluation process for a high-risk case while Fig. 10 and Fig. 11 illustrate the rule evaluation process for medium-risk and low-risk cases, respectively.

The 3D surface view for the rule that relates the COVID-19 infection risk to both fever and tiredness symptoms are demonstrated in Fig. 12. The dark blue surface represents a very low infection risk (less than 54\%) when both symptoms are low. The green surface represents a higher risk (between $54 \%$ and $60 \%$ ) when one of the two symptoms is high. The yellow surface represents a $65 \%$ risk when both symptoms are high. The 3D surface view for the rule that relates the COVID19 infection risk to both breathing difficulties and sore throat symptoms is demonstrated in Fig. 13. Unfortunately, the 3D surface viewer can show the relationship of the output variable with only two input variables and since high infection risk (more than 65\%) exists when at least 3 variables are high, this case cannot be viewed through this tool.

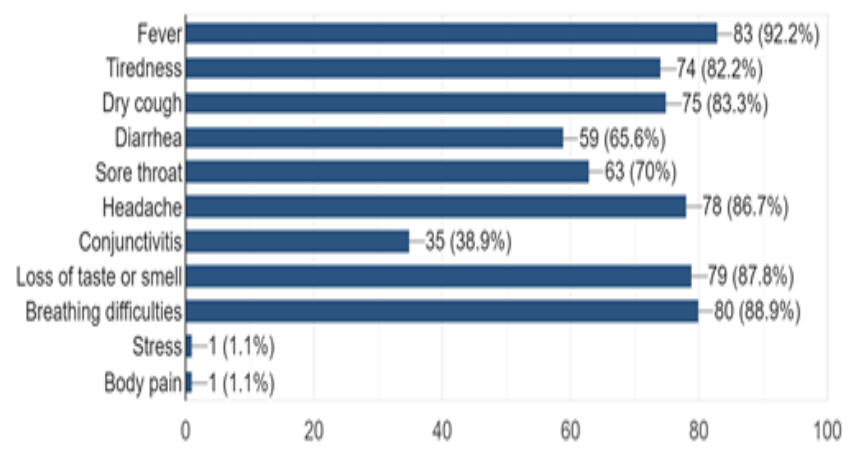

Fig. 7. The Results of Evaluating the Symptoms of COVID-19.

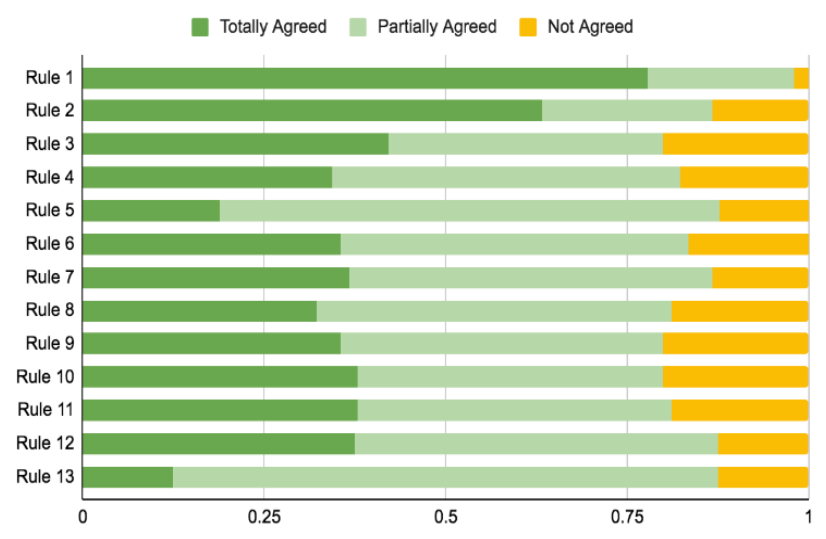

Fig. 8. Evaluation of Fuzzy Rules. 
TABLE II. System Testing With PosSible VALUES For PATIENT SyMPTOMS

\begin{tabular}{|c|c|c|c|c|c|c|c|c|c|c|c|}
\hline Case & $\begin{array}{l}\text { Fever } \\
(36- \\
\left.42^{\circ} \mathrm{C}\right)\end{array}$ & $\begin{array}{l}\text { Tiredness } \\
(0-5)\end{array}$ & $\begin{array}{l}\text { Dry } \\
\text { cough } \\
(0-5)\end{array}$ & $\begin{array}{l}\text { Diarrhea } \\
(0-5)\end{array}$ & $\begin{array}{l}\text { Sore } \\
\text { throat } \\
(0-5)\end{array}$ & $\begin{array}{l}\text { Headache } \\
(0-5)\end{array}$ & $\begin{array}{l}\text { Conjunctivitis } \\
(0-5)\end{array}$ & $\begin{array}{l}\text { Loss of } \\
\text { taste or } \\
\text { smell }(0-5)\end{array}$ & $\begin{array}{l}\text { Breathing } \\
\text { difficulties } \\
(0-5)\end{array}$ & $\begin{array}{l}\text { Output } \\
\text { (Risk } \\
\text { Percentage) }\end{array}$ & Risk level \\
\hline 1 & 38.5 & 5 & 5 & 5 & 5 & 5 & 5 & 5 & 5 & 84.84 & High \\
\hline 2 & 42 & 5 & 5 & 5 & 5 & 5 & 5 & 5 & 5 & 92.33 & Very high \\
\hline 3 & 39 & 3 & 3 & 3 & 3 & 3 & 3 & 3 & 3 & 73.35 & Medium \\
\hline 4 & 41 & 5 & 2 & 1 & 3 & 3 & 3 & 0 & 1 & 67.52 & Medium \\
\hline 5 & 37 & 1 & 0 & 1 & 0 & 3 & 3 & 5 & 4 & 51.50 & Low \\
\hline 6 & 40 & 5 & 3 & 3 & 3 & 3 & 3 & 3 & 3 & 87.14 & High \\
\hline 7 & 39.5 & 0 & 5 & 5 & 5 & 5 & 5 & 5 & 5 & 71.41 & Medium \\
\hline 8 & 40 & 5 & 4 & 3 & 3 & 3 & 3 & 3 & 3 & 89.37 & Very high \\
\hline 9 & 41 & 1 & 2 & 1 & 3 & 3 & 3 & 0 & 1 & 61.77 & Medium \\
\hline 10 & 38 & 1 & 0 & 1 & 0 & 3 & 3 & 0 & 1 & 51.73 & Low \\
\hline 11 & 40 & 5 & 4 & 1 & 3 & 3 & 3 & 0 & 1 & 73.22 & Medium \\
\hline 12 & 37 & 1 & 1 & 3 & 4 & 5 & 5 & 5 & 4 & 54.52 & Low \\
\hline 13 & 40 & 5 & 4 & 1 & 3 & 3 & 3 & 3 & 1 & 87.10 & High \\
\hline
\end{tabular}

(1)
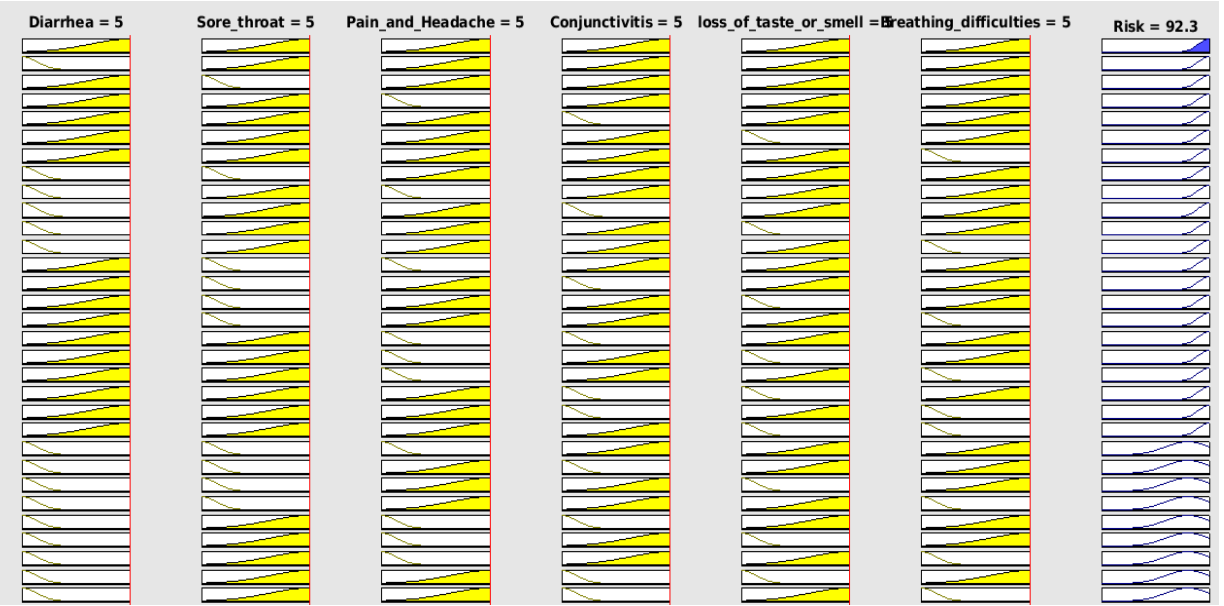

Fig. 9. Rule Evaluation for a High-Risk Case.

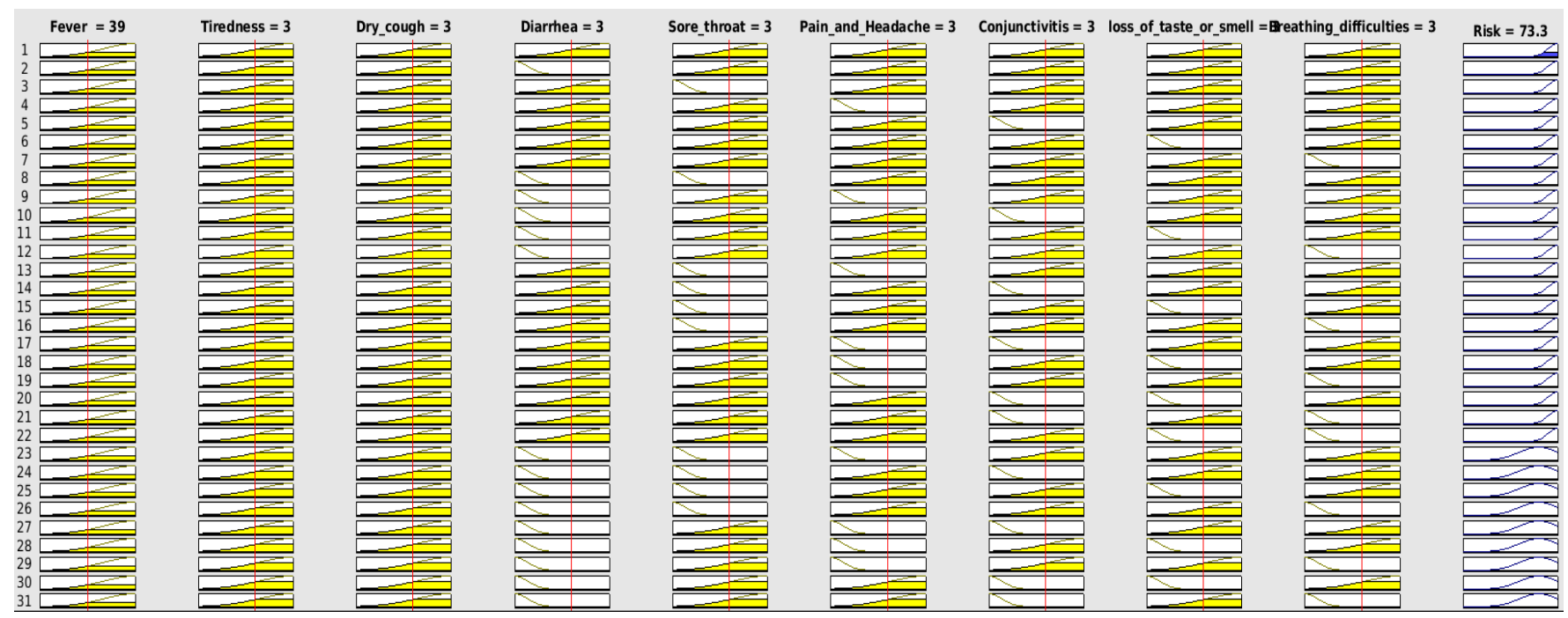

Fig. 10. Rule Evaluation for a Meduim-Risk Case. 


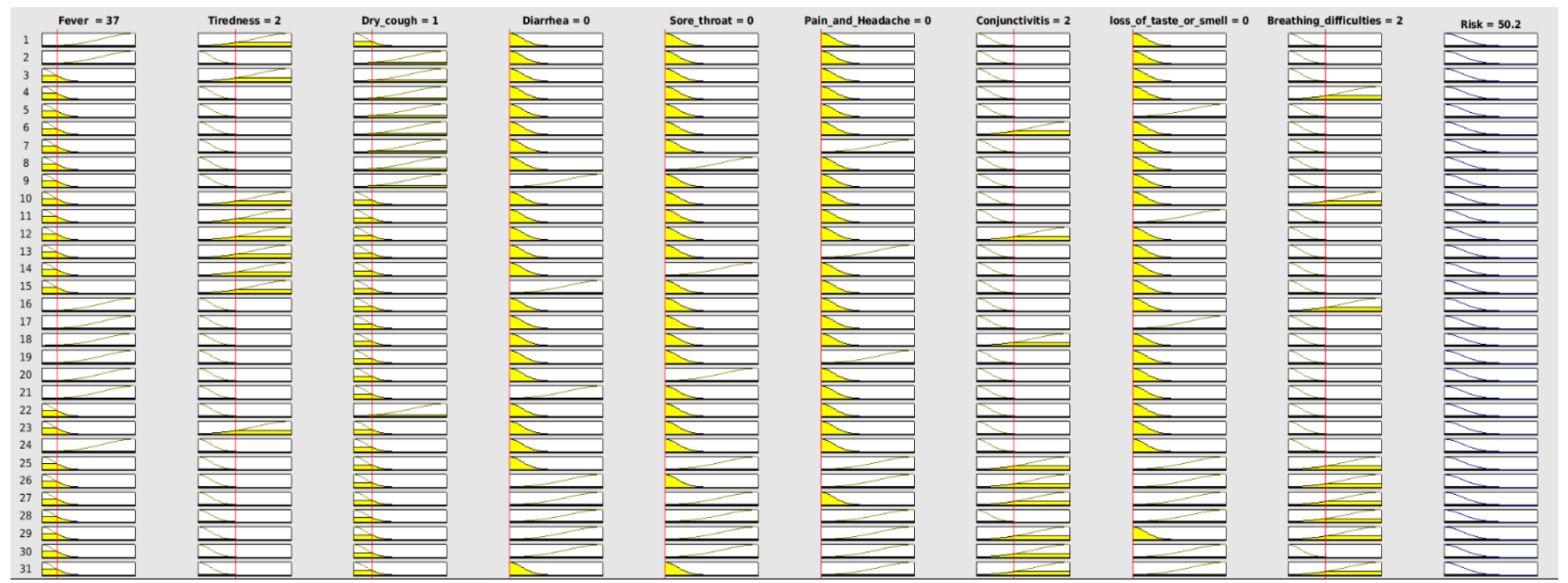

Fig. 11. Rule Evaluation for a Low-Risk Case.

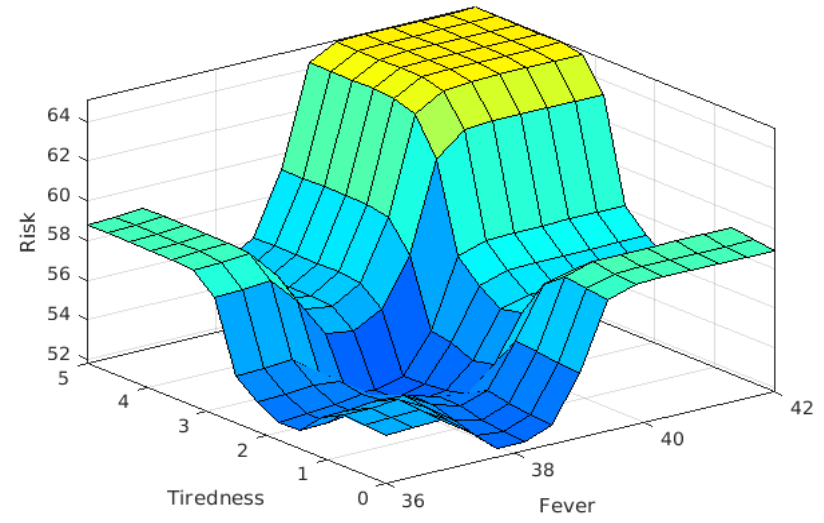

Fig. 12. COVID-19 Infection Risk vs. Fever and Tiredness.

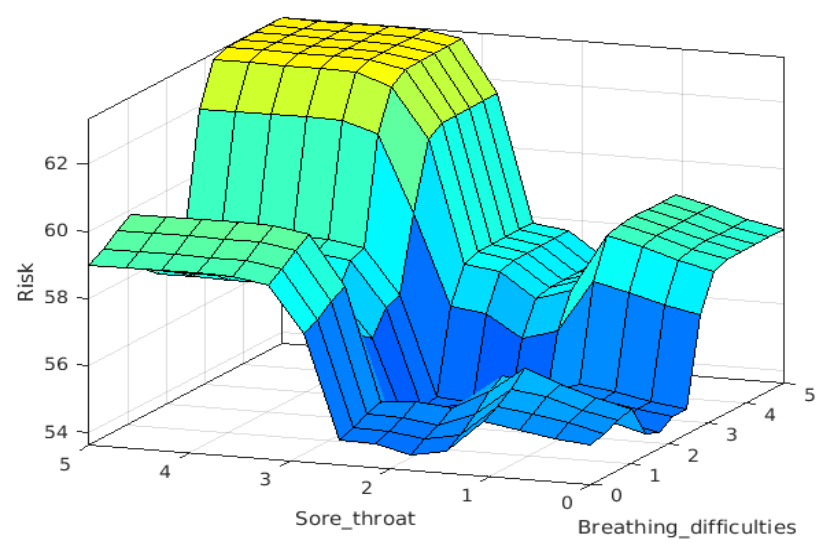

Fig. 13. COVID-19 Infection Risk vs. Breathing Difficulties and Sore Throat.

\section{CONCLUSIONS AND Future DireCtions}

We proposed a smart fuzzy inference system for the initial identification of COVID-19. The system infers the risk level of being COVID-19 infected based on the symptoms that appear on patients. The symptoms considered are fever, tiredness, and dry cough, diarrhea, sore throat, headache, conjunctivitis, loss of taste or smell, and breathing difficulties. This inference system can assist physicians in identifying the disease. Although the proposed system cannot provide a very accurate COVID-19 identification, it can be integrated with other identification techniques such as PCR test and CT scan to work together to confirm infected cases.

In future work, we are planning to implement this diagnosis system into a web application to allow individuals to perform self-diagnosis on their own cases. The work can be extended to include other patient data such as blood pressure, breathing air peak-flow-rate, and having a chronic disease. One of the interesting future directions is to apply data mining techniques to generate fuzzy rules from patient data.

\section{REFERENCES}

[1] Jamshidi, S. J. Zargaran, A. Talaei-Khoei and M. Kakavandi, "Modelling and Forecasting The Number of Confirmed Cases and Deaths from COVID-19 Pandemic in USA from April 12th to May 21st, 2020," medRxiv, 2020.

[2] "WHO Coronavirus Disease (COVID-19) Dashboard," December 2019. [Online]. Available: https://www.who.int/. [Accessed 1 March 2021].

[3] "Coronavirus Update," Worldometers, [Online]. Available: https://www.worldometers.info/coronavirus/. [Accessed 1 March 2021].

[4] "Centers for Disease Control and Prevention," U.S. Department of Health \& Human Services, 2020. [Online]. Available: https://www.cdc.gov/coronavirus/2019-ncov/index.html. [Accessed 1 March 2021].

[5] W.-j. Guan, Z.-y. Ni, Y. Hu, W.-h. Liang, C.-q. Ou, J.-x. He, L. Liu, H. Shan, C.-1. Lei, D. S. Hui and others, "Clinical characteristics of coronavirus disease 2019 in China," New England journal of medicine, vol. 382 , no. 18 , pp. 1708--1720, 2020.

[6] H. Arslan and H. Arslan, "A new COVID-19 Detection Method from Human Genome Sequences using $\mathrm{CpG}$ island Features and KNN Classifier," Engineering Science and Technology, an International Journal, 2021.

[7] "Journal of the American Medical Association," 2020. [Online]. Available: https://www.ama-assn.org/about/publicationsnewsletters/jama-network. [Accessed 1 March 2021].

[8] N. Dhiman and M. Sharma, "Fuzzy Logic Inference System for Identification and Prevention of Coronavirus (COVID-19)," International Journal of Innovative Technology and Exploring Engineering, 2020.

[9] T. Ai, Z. Yang, H. Hou, C. Zhan, C. Chen, W. Lv, Q. Tao, Z. Sun and L. Xia, "Correlation of chest CT and RT-PCR testing in coronavirus disease 2019 (COVID-19) in China: a report of 1014 cases," Radiology, p. 200642, 2020 . 
[10] "Emerging respiratory viruses, including COVID-19: methods for detection, prevention, response and control," World Health Organization, $2020 . \quad$ [Online]. Available: https://openwho.org/courses/introduction-to-ncov.

[11] L. Fan and S. Liu, "CT and COVID-19: Chinese experience and recommendations concerning detection, staging and follow-up," European Radiology, vol. 30, no. 9, p. 5214-5216, 2020.

[12] A. Tahamtan and A. Ardebili, "Real-time RT-PCR in COVID-19 detection: issues affecting the results," Expert Review of Molecular Diagnostics, vol. 20, no. 5, pp. 453-454, 2020.

[13] W. M. Shaban, A. H. Rabie, A. I. Saleh and M. Abo-Elsoud, "Detecting COVID-19 patients based on fuzzy inference engine and Deep Neural Network," Applied Soft Computing, vol. 99, p. 106906, 2021.

[14] Z. Ye, Y. W. Y. Zhang, Z. Huang and B. Song, "Chest CT manifestations of new coronavirus disease 2019 (COVID-19): a pictorial review," European Radiology, vol. 30, p. 4381-4389, 2020.

[15] S. a. F. A. a. J. M. Inui, N. Kunishima, S. Watanabe, Y. Suzuki, S. Umeda and Y. Uwabe, "Chest CT Findings in Cases from the Cruise Ship Diamond Princess with Coronavirus Disease (COVID-19)," Radiology: Cardiothoracic Imaging, vol. 2, no. 2, pp. 1-17, 2020.

[16] R. Yang, X. Li, H. Liu, Y. Zhen, X. Zhang, Q. Xiong, Y. Luo, C. Gao and W. Zeng, "Chest CT severity score: an imaging tool for assessing severe COVID-19," Radiology: Cardiothoracic Imaging, vol. 2, no. 2, pp. 1-23, 2020.

[17] W. Xia, J. Shao, Y. Guo, X. Peng, Z. Li and D. Hu, "Clinical and CT features in pediatric patients with COVID-19 infection: Different points from adults," Pediatric pulmonology, vol. 55, no. 5, pp. 1169--1174, 2020.

[18] H. Derakhshanfar, B. Sobouti, S. Fallah, Z. Soltantooyeh, S. Rahimi and S. Mirbaha, "A review on the effect of Coronavirus infections on respiratory problems in Children," Journal of Critical Reviews, vol. 7, no. 7, pp. 1-5, 2020.

[19] L. A. Zadeh, "Fuzzy sets," Information and control, vol. 8, no. 3, pp. 338--353, 1965.

[20] L. A. Zadeh, "Fuzzy sets," in Fuzzy sets, fuzzy logic, and fuzzy systems: selected papers by Lotfi A Zadeh, World Scientific, 1996, pp. 394--432.

[21] T. Heske and J. N. Heske, Fuzzy logic for real world design, Annabooks, 1996.

[22] M. F. Azeem, Fuzzy inference system: theory and applications, BoD-Books on Demand, 2012.

[23] A. Tagarakis, S. Koundouras, E. Papageorgiou, Z. Dikopoulou, S Fountas and T. Gemtos, "A fuzzy inference system to model grape quality in vineyards," Precision Agriculture, vol. 15, no. 5, pp. 555--578, 2014.

[24] F. Chabni, R. Taleb, A. Benbouali and M. A. Bouthiba, "The application of fuzzy control in water tank level using Arduino," International Journal of Advanced Computer Science and Applications, vol. 7, no. 4, pp. 261-265, 2016.

[25] V. D. B. Huynh, P. Nguyen, Q. Nguyen and P. T. Nguyen, "Application of fuzzy analytical hierarchy process based on geometric mean method to prioritize social capital network indicators," International Journal of Advanced Computer Science and Applications, vol. 9, no. 12, pp. 182$186,2018$.

[26] E. H. Mamdani and S. Assilian, "An experiment in linguistic synthesis with a fuzzy logic controller," International journal of man-machine studies, vol. 7, no. 1, pp. 1-13, 1975.

[27] E. H. Mamdani, "Application of fuzzy logic to approximate reasoning using linguistic synthesis," IEEE transactions on computers, vol. 12, pp. 1182--1191, 1977.

[28] Y. I. Daradkeh and I. Tvoroshenko, "Technologies for Making Reliable Decisions on a Variety of Effective Factors using Fuzzy Logic," International Journal of Advanced Computer Science and Applications, vol. 11, no. 5, pp. 43-50, 2020.

[29] S. M. Heakel and M. E. Khedr, "Realization of strong ports and shipping services in developing countries using multi-criteria selection algorithm," in 2010 International Conference on Logistics Systems and Intelligent Management (ICLSIM), 2010.
[30] S. Naaz, A. Alam and R. Biswas, "Effect of different defuzzification methods in a fuzzy based load balancing application," International Journal of Computer Science Issues (IJCSI), vol. 8, no. 5, p. 261, 2011.

[31] C.-S. Lee and M.-H. Wang, "A fuzzy expert system for diabetes decision support application," IEEE Transactions on Systems, Man, and Cybernetics, Part B (Cybernetics), vol. 41, no. 1, pp. 139--153, 2010.

[32] M. Mayilvaganan and K. Rajeswari, "Human Blood Pressure Classification Analysis Using Fuzzy Logic Control System in Datamining," International Journal of Emerging Trends $\ \&$ Technology in Computer Science (IJETTCS), vol. 3, no. 1, pp. 306-306, 2014.

[33] B. Ekong, I. Ifiok, I. Udoeka and J. Anamfiok, "Integrated Fuzzy based Decision Support System for the Management of Human Disease," International Journal of Advanced Computer Science and Applications, vol. 11, no. 2, 2020.

[34] X. Djam, G. Wajiga, Y. Kimbi and N. Blamah, "A fuzzy expert system for the management of malaria," International Journal of Pure and Applied Sciences and Technology, 2011.

[35] P. Sharma, D. Singh, M. K. Bandil and N. Mishra, "Decision support system for malaria and dengue disease diagnosis (DSSMD)," International Journal of Information and Computation Technology, vol. 3, no. 7, pp. 633--640, 2013.

[36] V. Chandra, "Fuzzy expert system for migraine analysis and diagnosis," International Journal of Science and Research, vol. 3, no. 6, pp. 956-959, 2014.

[37] A. Kumar, "Diagnosis of heart disease using Advanced Fuzzy resolution Mechanism," International Journal of Science and Applied Information Technology, vol. 2, no. 2, pp. 22--30, 2013.

[38] A. Adeli and M. Neshat, "A fuzzy expert system for heart disease diagnosis," in Proceedings of international multi conference of engineers and computer scientists, Hong Kong, 2010.

[39] S. Kumar and G. Kaur, "Detection of heart diseases using fuzzy logic," Int. J. Eng. Trends Technol.(IJETT), vol. 4, no. 6, pp. 2694--2699, 2013.

[40] T. Kasbe and R. S. Pippal, "Design of heart disease diagnosis system using fuzzy logic," in International Conference on Energy, Communication, Data Analytics and Soft Computing (ICECDS), 2017.

[41] N. Allahverdi, S. Torun and I. Saritas, "Design of a fuzzy expert system for determination of coronary heart disease risk," in Proceedings of the 2007 international conference on Computer systems and technologies, 2007.

[42] K. K. Oad, X. DeZhi and P. K. Butt, "A fuzzy rule based approach to predict risk level of heart disease," Global Journal of Computer Science and Technology, vol. 14, no. 3, 2014.

[43] S. Subbulakshmi, G. Marimuthu and M. N. Neelavathy, "A Fuzzy Logic Decision Support System for The Diagnosis of Heart Disease," IOSR Journal of Engineering (IOSRJEN), vol. 8, no. 8, pp. 70-77, 2018.

[44] N. Mishra and P. Jha, "A review on the applications of fuzzy expert system for disease diagnosis," International Journal of Advanced Research in Engineering and Applied Sciences, vol. 3, no. 12, pp. 28-43, 2014.

[45] K. Ali, A. Keleş and U. Yavuz, "Expert system based on neuro-fuzzy rules for diagnosis breast cancer," Expert systems with applications, vol. 38, no. 5, pp. 5719--5726, 2011.

[46] V. Balanica, I. Dumitrache, M. Caramihai, W. Rae and C. Herbst, "Evaluation of breast cancer risk by using fuzzy logic," University Politehnica of Bucharest Scientific Bulletin, Series C, vol. 73, no. 1, pp. 53-64, 2011.

[47] K. Latha, B. Madhu, S. Ayesha, R. Ramya, R. Sridhar and S. Balasubramanian, "Visualization of risk in breast cancer using fuzzy logic in matlab environment," International Journal of Computational Intelligence Techniques, vol. 4, no. 1, p. 114, 2013.

[48] K. Lavanya, M. S. Durai and N. Iyengar, "Fuzzy rule based inference system for detection and diagnosis of lung cancer," International Journal of Latest Trends in Computing, vol. 2, no. 1, pp. 165--171, 2011.

[49] I. Saritas, N. Allahverdi and I. U. Sert, "A fuzzy approach for determination of prostate cancer," International Journal of Intelligent Systems and Applications in Engineering, vol. 1, no. 1, pp. 1-7, 2013.

[50] S. Kolhe, R. Kamal, H. S. Saini and G. Gupta, "A web-based intelligent disease-diagnosis system using a new fuzzy-logic based approach for 
drawing the inferences in crops," Computers and Electronics in Agriculture, vol. 76, no. 1, pp. 16--27, 2011.

[51] A. Patel, J. Choubey, S. K. Gupta, M. Verma, R. Prasad and Q. Rahman, "Decision support system for the diagnosis of asthma severity using fuzzy logic," in Proceedings of the International MultiConference of Engineers and Computer Scientists (IMECS'12), 2012.

[52] S. K. Anand, R. Kalpana, S. Vijayalakshmi, S. Hartley and B. Bouchomeunier, "Design and implementation of a fuzzy expert system for detecting and estimating the level of asthma and chronic obstructive pulmonary disease," World Applied Sciences Journal, vol. 23, no. 2, pp. 213--223, 2013.

[53] N. Mishra, D. Singh, M. K. Bandil and P. Sharma, "Decision support system for asthma (DSSA)," International Journal of Information and Computation Technology, vol. 3, pp. 549--554, 2013.

[54] K. Sundararaman, V. Seerkalan and K. Rangarajan, "Risk Level of Asthma and Chronic Obstructive Pulmonary Disease Through Design of an Intelligent Type-2 Fuzzy Expert System," Instrumentation Mesure Métrologie, vol. 18, no. 6, pp. 583-590, 2019.

[55] S. R. Damirchi-Darasi, M. F. Zarandi, I. Turksen and M. Izadi, "Type-2 fuzzy rule-based expert system for diagnosis of spinal cord disorders," Scientia Iranica. Transaction E, Industrial Engineering, vol. 26, no. 1, pp. 455--471, 2019.

[56] M. A. Kadhim, M. A. Alam and H. Kaur, "Design and implementation of fuzzy expert system for back pain diagnosis," International Journal of
Innovative Technology \& Creative Engineering, vol. 1, no. 9, pp. 16-22, 2011.

[57] H. Zarei, A. V. Kamyad and A. A. Heydari, "Fuzzy modeling and control of HIV infection," Computational and mathematical methods in medicine, vol. 2012, 2012.

[58] A. Imianvan, U. Anosike and J. Obi, "An Expert System for the Intelligent Diagnosis of HIV/AIDs Using Fuzzy Cluster Means Algorithm," Global Journal of Computer Science and Technology, 2011.

[59] T. Faisal, M. N. Taib and F. Ibrahim, "Adaptive Neuro-Fuzzy Inference System for diagnosis risk in dengue patients," Expert Systems with Applications, vol. 39, no. 4, pp. 4483--4495, 2012.

[60] D. Saikia and J. C. Dutta, "Early diagnosis of dengue disease using fuzzy inference system," in 2016 International Conference on Microelectronics, Computing and Communications (MicroCom), 2016.

[61] M. Alrashoud, "Hierarchical Fuzzy Inference System for Diagnosing Dengue Disease," in 2019 IEEE International Conference on Multimedia I\& Expo Workshops (ICMEW), 2019.

[62] "What Is The Normal Body Temperature: Babies, Kids, Adults, And More," Healthline, 2020. [Online]. Available: https://www.healthline. $\mathrm{com} /$ health/what-is-normal-body-temperature\#temperature-range.

[63] "Measuring Your Peak Flow Rate," American Lung Association, 2020. [Online]. Available: https://www.lung.org/lung-health-diseases/lungdisease-lookup/asthma/living-with-asthma/managing-asthma/measuringyour-peak-flow-rate. [Accessed 1 March 2021]. 